\title{
O CRITÉRIO TEMPORAL DE INCIDÊNCIA TRIBUTÁRIA DO IMPOSTO SOBRE TRANSMISSÃO CAUSA MORTIS E DOAÇÃO - ITCMD
}

\section{THE TEMPORAL CRITERION OF TAX INCIDENCE OF THE STATE AND GIFT TAX - (ITCMD)}

\author{
${ }^{1}$ Marcos Aurélio Pereira Valadão \\ ${ }^{2}$ Flavio Chaib
}

\begin{abstract}
RESUMO
O artigo tem por objetivo analisar o critério temporal de incidência tributária do imposto sobre a transmissão causa mortis e doação - ITCMD, com especial referência às Súmulas ns. 112, 113 e 114 do STF. Com este objetivo o artigo parte da metodologia analítica da regramatriz de incidência, com foco no aspecto temporal. Metodologicamente trata-se de pesquisa bibliográfica e documental, por meio da análise de julgados dos tribunais superiores, visando elucidar da hipótese levantada. Dedica-se especial atenção à questão da aplicação da norma no tempo, e a aplicação das referidas súmulas, que podem estar em dissonância com a realidade atual.
\end{abstract}

Palavras-chave: Imposto causa mortis e doações, Fato gerador, Momento de ocorrência, Súmulas

\begin{abstract}
The article aims to analyze the temporal criterion of the tax incidence of state and gift tax (ITCMD), with particular reference to Judicial Precedents ns. 112, 113 and 114 (STF). The article uses the analytical methodology of the matrix rule for tax incidence, focusing on the temporal aspect. Methodologically it is a and bibliographical and documentary research, by analysing superior court cases to elucidate the hypothesis raised. The article dedicates special attention to the issue of the application of the rule in time, and the application of cited precedents, which may be not be in line with the current reality.
\end{abstract}

Keywords: State and gift tax, Taxable event, Moment of occurrence, Judicial precedentes

\footnotetext{
${ }^{1}$ Doutor em Direito pela Southern Methodist University, SMU - EUA, (Estados Unidos). É professor e pesquisador da Universidade Católica de Brasília, UCB - DF, (Brasil). E-mail: profvaladao@yahoo.com.br

${ }^{2}$ Mestrando em Direito pela Universidade Católica de Brasília, UCB -DF, (Brasil). E-mail: flchaib@gmail.com
} 


\section{INTRODUÇÃO}

Apesar de pouco explorado pela doutrina, a arrecadação do imposto sobre heranças e doações vem crescendo nos últimos anos. O estudo do imposto sobre heranças ganha importância mundial, como destaca Thomas Piketty (PIKETTY, 2014, p. 369) em todas sociedades, existem duas maneiras principais de se obter conforto material: por meio do trabalho ou da herança, e a tributação sobre a herança tem grande relevância na distribuição da renda no longo prazo. No Brasil, as administrações tributárias que vem revisando a forma de tributar e fiscalizar o ITCMD, aumentando suas alíquotas, definindo os critérios de progressividade, estabelecendo prazos e inserindo obrigações acessórias para facilitar a fiscalização e aumentar a arrecadação, e assim, calorosas discussões vem ganhando destaque na doutrina e nos tribunais superiores.

Em face disto, vale fazer uma revisão sobre os principais pontos de conflitos em matéria da tributação do imposto sobre a transmissão causa mortis e doação.

Nesse sentido, o presente artigo faz uma análise sobre o critério temporal do fato gerador do ITCMD. A priori, parece simples a definição sobre o momento de ocorrência do fato gerador do ITCMD, no núcleo transmissão causa mortis, aqui denominado imposto sobre herança, considerando que o evento morte abre-se a sucessão hereditária. Porém a complexidade decorre do fato que neste momento o fisco não tem os elementos necessários para efetuar o lançamento do crédito tributário. Daí, as legislações estaduais, que regem a matéria, incluírem dispositivos elegendo termos iniciais, prazos para lançamentos e para pagamento do imposto, etc. Ocorre que, em razão desses dispositivos legais, surgiram demandas judiciais que acabaram desaguando no Supremo Tribunal Federal - STF, que assim, editou as súmulas 112, 113 e 114, utilizadas para solucionar conflitos envolvendo discussões sobre definição de alíquotas, base de cálculo e contagem inaugural do prazo prescricional e decadencial para a exigibilidade do ITCMD.

Assim, para melhor compreensão desta análise, em termos metodológicos foi elaborada pesquisa bibliográfica e documental a respeito do critério temporal, elencando o que dispõe a legislação tributária, e em seguida explorou-se especificamente estes aspectos no 
que diz respeito ao imposto sobre herança, confrontando o que dispõe as legislações tributárias e civil.

Este estudo justifica-se pelo fato de apontar uma possível solução de conflitos quanto a aplicação da legislação no tempo, tento como objetivo principal mostrar a posição da doutrina e da jurisprudência dos tribunais, e em face disto, fazer uma análise crítica das súmulas elencadas, questionando-as sobre suas aplicabilidades em tempos atuais.

Por fim, aponta as conclusões sobre o estudo e sugere alternativas legais, com objetivo de reduzir os conflitos de dar melhor aplicabilidade e eficácia à norma tributária.

\section{A REGRA-MATRIZ DE INCIDÊNCIA TRIBUTÁRIA E O ITCMD}

Da subsunção da norma jurídica que prescreve a incidência tributária sobre o fato concreto surge a relação jurídico-tributária. Essa relação vincula o Estado (Fisco) e o particular (contribuinte), ainda que inexista o dever de pagar tributo, existirá uma obrigação tributária. Ocorre que esta relação advém do império de uma norma jurídica que a estabelece como consequência da realização do descrito no texto legal.

Nesse sentido, CASSONE (2015, p. 138) explica o fenômeno da subsunção ao dizer que: só há fato gerador se o fato ocorrido contiver todos os elementos descritos pela Lei, devendo tais elementos, em consequência, corresponder rigorosamente à descrição que a lei faz do tipo tributário

A expressão "regra matriz de incidência tributária" foi utilizada por CARVALHO (2008, p.146), que assim descreveu:

a regra matriz é apresentada como um método, um recurso para compreensão do fenômeno jurídico-tributário. Partindo da premissa segundo a qual toda norma jurídica tem estrutura lógica de um juízo hipotético, ao qual é ligada uma consequência jurídica, quando acontecido o fato precedente, chega-se ao esquema proposto.

Assim, esse método esquematiza dois polos, o antecedente ou proposição descritiva que se interliga com uma proposição prescritiva, o consequente. Nesse diapasão, descreve PRADO (2009, p.45):

no ato intelectual da construção da norma tributária em sentido estrito, o cientista deverá identificar as duas proposições que obrigatoriamente a comporão: uma proposição descritiva (antecedente) conectada a uma proposição prescritiva (consequente), competindo-lhe, ainda, apontar os seus aspectos essenciais: no antecedente (hipótese ou descritor), o critério material (comportamento de uma 
pessoa), condicionado no tempo (critério temporal) e no espaço (critério espacial); consequente (prescritor), os critérios pessoal (sujeito ativo e passivo) e quantitativo (base de cálculo e alíquota).

Dessa forma, essa proposta teórica desenvolvida por CARVALHO $(2008$, p.502) permite estudar com profundidade a estrutura lógica e científica da norma jurídica que estabelece a relação jurídico-tributária, identificando a proposição descritiva, que antecede a relação, apontando o "fato gerador", os critérios: material, temporal e espacial, bem como, a proposição prescritiva, que é a consequência da concretização da norma, apontando os critérios: pessoal e quantitativo.

no polo antecedente, o esquema da regra matriz tributária aponta a descrição hipotética
de uma situação que, concretizada, motivará o surgimento da relação em questão. O
antecedente é corriqueiramente denominado de "fato gerador".(...)
Por sua vez, o prescritor da regra matriz de incidência apresenta a relação jurídica que
se instaura a partir da concretização do "fato gerador". Essa relação, como se verá,
tem a natureza obrigacional, implicando que o sujeito passivo tem a obrigação de
pagar um valor ao sujeito ativo. Surgem assim, os critérios pessoal (i.e.: as pessoas
que se vinculam pela relação jurídica assim estabelecida - sujeito ativo e passivo)
e quantitativo (o montante a ser recolhido, expresso pela base de cálculo e a alíquota).

Com efeito, a teoria da regra-matriz tributária foi utilizada por nossa legislação, tendo o artigo 97 do Código Tributário Nacional- CTN, contemplado o Princípio da Legalidade, ao dispor:

Art. 97. Somente a lei pode estabelecer:

I- $\quad$ a instituição de tributos, ou a sua extinção;

II- a majoração de tributos, ou a sua redução, ressalvado o disposto nos arts. (...);

III- a definição do fato gerador da obrigação tributária principal, ressalvado o disposto no inciso I do $\S 3^{\circ}$ do art. 52, e do seu sujeito passivo;

IV- a fixação da alíquota e da sua base de cálculo (...)

Assim, o antecedente material (“fato gerador") e os consequentes (pessoal: sujeito passivo e quantitativo: base de cálculo e alíquota) da regra-matriz estão subordinados a legalidade.

O artigo 114 do CTN define o fato gerador da obrigação principal como sendo a situação definida em lei como necessária e suficiente à sua ocorrência. Portanto, é o fato descrito em lei contendo todos os elementos que identifique sua perfeita identificação. Diversos autores adotam outras terminologia, no entanto, independente das asserções doutrinárias, discorre COÊLHO (2015) que acontecido o fato previsto na hipótese legal, o mandamento que era abstrato, virtual, torna-se atuante e incide, produzindo efeitos no mundo real, instaurando relações jurídicas. 
Após essas breves considerações acerca da regra-matriz de incidência tributária, examinar-se-á o artigo 155 do texto constitucional, que rege o ITCMD, para posterior confronto dos critérios da regra-matriz de incidência tributária disposta na legislação estadual.

Art. 155 Compete aos Estados e ao Distrito Federal instituir impostos sobre:

I - transmissão causa mortis e doação, de quaisquer bens ou direitos;

$\S 1^{\circ} \mathrm{O}$ imposto previsto no inciso I:

I - relativamente a bens imóveis e respectivos direitos, compete ao

Estado da situação do bem, ou ao Distrito Federal

II - relativamente a bens móveis, títulos e créditos, compete ao Estado onde se processar o inventário ou arrolamento, ou tiver domicílio o doador, ou ao Distrito Federal;

III - terá competência para sua instituição regulada por lei complementar: a) se o doador tiver domicilio ou residência no exterior;

b) se o de cujus possuía bens, era residente ou domiciliado ou teve o seu inventário processado no exterior;

IV - terá suas alíquotas máximas fixadas pelo Senado Federal;

O texto constitucional trouxe algumas inovações em relação à Constituição de 1967/1969, no entanto manteve a competência dos Estados-membros e do Distrito Federal para tributação sobre transmissão causa mortis e inter vivos a título gratuito (doação) de bens imóveis, estendendo-a, para os bens móveis. Ademais, determinou a regulamentação por lei complementar nas hipóteses definidas nas alíneas "a" e "b" do inciso III. E por fim, estabeleceu a competência para atribuir as alíquotas máximas ao Senado Federal.

Vale destacar que o dispositivo prescreve dois núcleos: a) transmissão causa mortis e b) doação. Para COÊLHO (2015, p. 461), ao comentar o artigo 35 do Código Tributário Nacional, afirma que "o imposto como ideado no CTN não mais existe. A CF/88 atribuiu aos Estados um imposto causa mortis amplo sobre a transmissão de quaisquer bens ou direitos". Nesse sentido, PRADO (2009, p.35) conclui “o ITCM não incide sobre bens isoladamente considerados, mas sobre o quinhão recebido pelo herdeiro, o que pressupõe o exame do acervo hereditário na sua integralidade."

O ITCMD é caracterizado com imposto de natureza real, ou seja, é um imposto em que se toma em consideração apenas a coisa sobre a qual recai o tributo, sem levar em conta as condições particulares dos contribuintes. Em sentido contrário, o imposto de natureza pessoal é aquele em que são sopesadas as qualidades individuais dos contribuintes para sua gradação.

No entanto, vale ressaltar a posição TORRES ( 2007, p. 228), ele destaca que o "princípio da personalização", expresso pelo agravamento da tributação de acordo com o 
afastamento entre herdeiro e de cujus na linha da sucessão, presente em diversas legislações estrangeiras, fez com que imposto causa mortis tenha se transformado em um tributo pessoal, quando antes era real.

\section{ANTECEDENTE TEMPORAL DO IMPOSTO DE TRANSMISSÃO DO NÚCLEO}

\section{CAUSA MORTIS}

Qual o marco temporal que a norma tributária elegeu para definir a ocorrência do fato gerador do ITCMD pela transmissão de bens ou direitos em razão da morte?

Segundo CARVALHO (2002, p.142) a classificação jurídica com base no critério temporal das "hipóteses tributarias" são: a) as que definem (expressa ou implicitamente o momento de ocorrência do fato jurídico tributário; b) que não definem momento específico, podendo acontecer em qualquer circunstância de tempo.

A princípio, deve-se recorrer ao conceito do direito civil para identificar o momento de transmissão da herança, no núcleo causa mortis, assim dispõe o artigo 1.784 do Código Civil, in verbis: "Aberta a sucessão, a herança transmite-se, desde logo, aos herdeiros legítimos e testamentários".

Portanto, a priori, o evento morte é o marco temporal para a incidência do imposto sobre a transmissão causa mortis de quaisquer bens ou direitos, inclusive sobre a morte presumida, em que se abre a sucessão provisória.

Nesse diapasão, MACHADO (2010, p.378) afirma que:

a morte opera automaticamente a transmissão da propriedade de todos os bens que a pessoa natural possui. Seja por força de lei, simplesmente, seja por força de ato de última vontade do autor da herança. A formalização dessa transmissão de propriedade ordinariamente ocorre mediante o processo de inventário, e no âmbito deste o imposto é lançado pela autoridade competente e pago pelos interessados.

Discorrendo sobre o aspecto temporal da hipótese de incidência do ITCMD, FERNANDES $(2013$, p.84) relata a importância ao fato morte, por ser ele o evento - base de incidência da regra: 
temos que a abertura da sucessão é o ponto de partida de todo o fenômeno hereditário. É começar o fato sucessório. O elemento essencial de toda a disciplina jurídica de transmissão por morte é o próprio fato da sucessão, como continuação nos sucessores das relações jurídicas que compõem o patrimônio do falecido. (...) $\mathrm{O}$ fato jurídico morte é o gerador da sucessão, ou seja, a substituição do sucedido pelo sucessor na titularidade do patrimônio que se transmite opera de imediato com o fato jurídico morte.

No caso da morte presumida, DINIZ (2008, p.49) relata declaração judicial é admitida "para viabilizar o registro do óbito, resolver problemas jurídicos gerados com o desaparecimento e regular a sucessão causa mortis, apenas depois de esgotadas todas as buscas e averiguações, devendo a sentença fixar a data provável do óbito".

O Código Civil de 2002 autoriza ao juiz a declaração de morte presumida quando for extremamente provável a morte de quem estava em perigo de vida. Outra hipótese, em que se autoriza a declaração de morte presumida é quando alguém, desaparecido em campanha (ação militar) ou feito prisioneiro, não for encontrado até dois anos após o término da guerra.

Segundo o Código Civil, assim como o óbito deverá ter assento em Registro Público (art. $\left.9^{\circ}, \mathrm{I}, \mathrm{CC}\right)$, também a declaração de morte presumida será registrada (art. $\left.9^{\circ}, \mathrm{IV}, \mathrm{CC}\right)$.

Outra possibilidade para se declarar a morte presumida é com declaração de ausência, quando o Código Civil autoriza, na última parte de seu art. $6^{\circ}$ : “(...) presume-se esta (a morte), quanto aos ausentes, nos casos em que a lei autoriza a abertura de sucessão definitiva.

Identificado o momento de ocorrência do fato gerador do ITCMD, deve-se observar quais as consequências e efeitos desta definição, isto porque, pergunta-se: seria possível o Fisco identificar e apurar o cálculo do ITCMD, sem que haja a realização do inventário, o levantamento dos bens, dos direitos, dos herdeiros e dos legatários?

Resta claro, que com o evento morte, abre-se a sucessão, porém, em tese, o Fisco não tem os elementos necessários para constituição do crédito, ou seja, não é possível verificar as circunstâncias materiais necessárias para constituir-se o crédito tributário.

Nesse sentido, afirma PRADO (2009, p.111), in verbis:

embora tenha sido definido que o marco temporal da hipótese tributária ocorre com a abertura da sucessão, afirmamos que a apuração da base de cálculo do ITCM é um fenômeno complexo, não dimensionável naquele instante, concluindo que somente com a realização do inventário e da partilha de bens é possível identificar os herdeiros e apurar o efetivo acréscimo patrimonial por ele experimentado. 
Vale ressaltar que o sistema jurídico em vigor estabelece que a transmissão aos herdeiros seja viabilizada por meio do inventário ou arrolamento, ademais o Código de Processo Civil estabelece o prazo de 60 (sessenta) dias a contar da abertura da sucessão, para o processo de inventário e partilha seja aberto.

Pelo exposto, resta claro que no caso do ITCMD, em regra, caberá ao legislador estabelecer o momento em que se deve reputar acontecida a materialidade do imposto. No entanto, o instante do nascimento da obrigação tributária deve guardar efetivo vínculo com a matéria objeto de tributação, eis que todos os aspectos da norma são intrinsecamente ligados e indissociáveis.

O lançamento do ITCMD, no caso do inventário, conta com o auxílio do contribuinte, ao informar e declarar o que consta no processo de inventário, sem no entanto, efetuar pagamento prévio do imposto, de acordo com a legislações estaduais. Assim, em razão do contribuinte ao prestar as informações sobre matéria de fato indispensáveis à efetivação do lançamento, configura-se o lançamento denominado por declaração. Porém, sujeito a homologação do cálculo pelo fisco.

Vale lembrar o que dispõe o CTN a respeito:

\footnotetext{
Art. 116. Salvo disposição de lei em contrário, considera-se ocorrido o fato gerador e existentes os seus efeitos:

I - tratando-se de situação de fato, desde o momento em que o se verifiquem as circunstâncias materiais necessárias a que produza os efeitos que normalmente lhe são próprios;

II - tratando-se de situação jurídica, desde o momento em que esteja definitivamente constituída, nos termos de direito aplicável.
}

Portanto, da análise sobre o aspecto temporal da incidência do ITCMD - causa mortis, têm-se cinco instantes de relevância e intrinsicamente ligados, na aplicação da norma tributária em relação à incidência e à apuração do valor desse imposto: a) o evento morte; b) a formalização ou abertura do inventário; c) requerimento ou conhecimento da fazenda pública; d) homologação do cálculo; e) momento da partilha.

A partir destes cinco instantes elencados acima, o fisco deve observar a regra a ser aplicada no caso concreto.

Em tese, a regra do tempus regit actum consagra a aplicação da norma vigente à época dos fatos da ocorrência do fato gerador. Isso porque será a partir destes momentos que o legislador irá dispor para considerar a aplicação efetiva da norma ao caso concreto. 
Nesse sentido, SCHOUERI (2015, p.804) esclarece:

vigente uma lei, deve ser ela aplicada. Daí o imediato raciocínio de que concretizando-se a hipótese descrita no antecedente normativo de lei vigente, cabe sua aplicação, i.é, desenrola-se o consequente normativo. No caso das leis que instituem tributos, dir-se-á presente o fato jurídico tributário, daí implicando o surgimento da relação jurídico-tributária.

Foi nessa linha que o artigo 105 do Código Tributário Nacional estabeleceu que a legislação tributária aplica-se imediatamente aos fatos geradores futuros e aos pendentes, assim entendidos aqueles cuja ocorrência tenha tido início mas não esteja completa nos termos do artigo 116 .

O sentido da aplicação imediata deste artigo segundo MACHADO (2010, p.90) é:

A rigor, a norma do art. 105, que admite a aplicação da lei ao fato gerador pendente, não foi recepcionada pela Constituição Federal de

1988, porque configura evidente hipótese de retroatividade no que diz respeito aos elementos de fatos já consumados...A lei nova que que agrava ônus do contribuinte somente deve ser aplicada aos fatos geradores ainda não iniciados. Em outras palavras, a lei que agrava os encargos do contribuinte somente deve ser aplicada no ano seguinte de sua publicação.

Faz-se mister esclarecer que o âmbito temporal de validade da norma deve distinguir os fatos ocorridos antes e depois do estabelecimento desta. Em regra, a norma refere-se a acontecimentos futuros, porém, ela poderá ser aplicada a fatos pretéritos, daí falar em "força retroativa" de uma norma jurídica.

Quanto a aplicação retroativa da lei tributária, a regra é a irretroatividade, no entanto, o art. 106 do CTN trouxe as hipóteses de aplicação a ato ou fato pretérito:

A lei aplica-se a ato ou fato pretérito:

I - em qualquer caso, quando seja expressamente interpretativa, excluída a aplicação de penalidade à infração dos dispositivos interpretados;

II - tratando-se de ato não definitivamente julgado:

a) quando deixe de defini-lo como infração;

b) quando deixe de tratá-lo como contrário a qualquer exigência de ação ou omissão, desde que não tenha sido fraudulento e não tenha implicado em falta de pagamento de tributo;

c) quando lhe comine penalidade menos severa que a prevista na lei vigente ao tempo da sua prática.

Vale destacar que a retroatividade benigna advém do Direito Penal, no qual aplica-se a lei mais benéfica com intuito de favorecer o agente. No entanto, em matéria tributária, a retroatividade é aplicada quando a lei cominar penalidades menos severa, e portanto, não alcança a aplicação de alíquotas, mas tão somente a aplicação de penalidades. 
Em matéria de ITCMD, a ausência de lei complementar que regule norma geral, fez com que os Estados e o Distrito Federal legislassem de forma supletiva, dando margem a instituição de um pandemônio de dispositivos sobre a consideração do momento de ocorrência do fato gerador.

Como panaceia para todos os males foram editadas pelo STF, algumas súmulas, objeto de análise no próximo tópico.

\section{CONSIDERAÇÕES Às SÚMULAS 112, 113 E 114 DO SUPREMO TRIBUNAL FEDERAL - STF.}

Em síntese, estas súmulas dispõe sobre o momento de aplicação da regra de incidência do ITCMD e são utilizadas para solucionar conflitos envolvendo discussões sobre definição de alíquotas, base de cálculo e contagem inaugural do prazo prescricional e decadencial para a exigibilidade do ITCMD.

\subsection{SÚMULA 112/STF. O imposto de transmissão "causa mortis" é devido pela alíquota vigente ao tempo da abertura da sucessão.}

No julgamento que tratava, originariamente, de agravo de instrumento interposto pelo Estado do Rio Grande do Sul contra decisão que, nos autos do inventário dos bens deixados por João S. R. e de Maria S.R., o STJ determinou a aplicação da alíquota de 1\% para o cálculo do ITCD, com base na legislação vigente à época da apuração do imposto, em vez de aplicar a alíquota de $4 \%$ prevista na lei vigente na data da abertura da sucessão (morte do de cujus).

TRIBUTÁRIO - ITCD - FATO GERADOR - PRINCÍPIO DA SAISINE - SÚMULA 112/STF. 1. Cinge-se a controvérsia em saber o fato gerador do ITCD - Imposto de Transmissão Causa Mortis. 2. Pelo princípio da saisine, a lei considera que no momento da morte o autor da herança transmite seu patrimônio, de forma íntegra, a seus herdeiros. Esse princípio confere à sentença de partilha no inventário caráter meramente declaratório, haja vista que a transmissão dos bens aos herdeiros e legatários ocorre no momento do óbito do autor da herança. 3. Forçoso concluir que as regras a serem observadas no cálculo do ITCD serão aquelas em vigor ao tempo do óbito do de cujus. 4. Incidência da Súmula 112/STF. Recurso especial provido. $^{1}$

\footnotetext{
1 STJ - REsp: 1142872 RS 2009/0104234-6, Relator: Ministro HUMBERTO MARTINS, Data de Julgamento: 20/10/2009, T2 - SEGUNDA TURMA, Data de Publicação: DJe 29/10/2009)
} 
Pelo que se extrai da referida súmula, em atenção ao princípio do saisine, de origem francesa, pelo qual se estabelece que a posse dos bens do "de cujus" se transmite aos herdeiros, imediatamente, na data de sua morte, a lei considera como o momento de ocorrência do fato gerador da incidência do ITCMD, o evento morte, daí concluir que as regras a serem observadas no cálculo do ITCD serão aquelas ao tempo do óbito do de cujus.

E se alíquota da data do evento morte fosse maior? Aplicar-se-ia a mais favorável ao contribuinte (retroatividade da norma benigna)?

E agora com a instituição de alíquotas progressivas, como aplicar-se-ia a súmula?

Dessa forma, com base nesta súmula era de se esperar que todas as regras de apuração do cálculo do imposto fossem com base nas normas à época do evento morte, e da mesma forma, que este fosse o termo a quo na contagem dos prazos. Porém, não é este o entendimento dos tribunais, conforme esposados nas súmulas seguintes.

\subsection{SÚMULA 113/STF. O imposto de transmissão "causa mortis" é calculado sobre o valor dos bens na data da avaliação.}

No julgamento de recurso especial $\mathrm{n}^{0}$ 57.742- PR fundado no artigo 105, a, da Constituição Federal, contra acórdão proferido pelo Tribunal de Justiça do Estado do Paraná, o STJ proferiu seguinte decisão:

TRIBUTÁRIO. IMPOSTO DE TRANSMISSÃO CAUSA MORTIS. SÚMULA 113/STF.CORREÇÃO MONETÁRIA. CABIMENTO. 1. "O imposto de transmissão causa mortis é calculado sobre o valor dos bens na data da avaliação" (Súmula 113/STF). 2. Não recolhido o valor na época própria, torna-se indispensável a necessária atualização do valor. É pacífico o entendimento de que a correção monetária da base de cálculo não implica alteração do fato gerador. Precedentes. 3.

Recurso especial conhecido e improvido. ${ }^{2}$

O fato gerador do ITCMD incide sobre a transmissão dos bens com a abertura da sucessão. Nesse momento (abertura da sucessão/morte do de cujus), ainda não é exigível o pagamento da exação. O art. 38 do Código Tributário Nacional é bastante claro ao estabelecer que a base de cálculo do imposto é o valor venal do dos bens ou direitos transmitidos.

\footnotetext{
2 STJ, REsp: 57.742 PR 1994/0037618-9 Relator: Ministro CASTRO MEIRA, Data de Julgamento: 04/05/2004, T2 - SEGUNDA TURMA
} 
Dessa forma, deve-se concluir que somente com a liquidação da herança, via sentença judicial, é que se definem quais os bens que efetivamente foram transmitidos aos herdeiros.

Portanto, observe que aplica-se a regra da definição da base de cálculo não a do evento morte, mas sim a do momento do lançamento do imposto.

Daí questiona-se: cabe ao fisco aguardar o momento que o contribuinte entender para requerer o lançamento? E o instituto da decadência?

\subsection{SÚMULA 114/STF. O imposto de transmissão "causa mortis" não é exigível antes da homologação do cálculo.}

Pelo exposto, pode-se concluir que a obrigação tributária, existente desde a data do óbito, somente é exigível o seu cumprimento após a homologação do cálculo por sentença judicial.

Ocorre que, diversas legislações estaduais $(\mathrm{MG}, \mathrm{PI}, \mathrm{SP}, \ldots)$ estabelecem prazos para pagamento do imposto, tendo como termo a quo o da abertura da sucessão. Nesse sentido, resta claro que tais dispositivos consideram exigível o crédito tributário a partir da abertura da sucessão, independente de julgamento.

Ademais, vale destacar que a Constituição atribuiu capacidade plena aos estadosmembros para legislarem sobre direito tributário, visto que não existe lei federal sobre normas gerais que trate do referido imposto. Assim, sendo o estado-membro competente para legislar sobre direito tributário, com competência legislativa plena, segundo estipula o caput do art. $6^{\circ}$ do Código Tributário Nacional. Assim, não pode o Código de Processo Civil disciplinar matéria tributária relativa ao ITCMD, não podendo, por consequência, estabelecer o momento de recolhimento, bem como sua exigibilidade, confrontando norma tributária específica.

Ressalta-se que este não é o entendimento que tem prevalecido pelos tribunais superiores. 


\section{CONCLUSÕES}

Com as recentes alterações nas legislações tributárias, reacende as discussões sobre alguns pontos conflitantes, e um deles, conforme esposado é em relação aos dispositivos nas legislações estaduais sobre o momento de ocorrência do fato gerador do ITCMD.

Com base na análise da regra-matriz de incidência tributária e na posição doutrinária e jurisprudencial restou evidente que o momento de ocorrência do fato gerador do imposto sobre herança é o evento morte.

Porém, questionou-se se seria possível o Fisco identificar e apurar o cálculo do ITCMD, sem que haja a realização do inventário, o levantamento dos bens, dos direitos, dos herdeiros e dos legatários?

Daí, concluir-se desta impossibilidade tendo em vista que a apuração da base de cálculo do ITCMD ser um fenômeno complexo, não dimensionável naquele instante. Assim, o físco, naquele momento, não dispõe dos elementos necessários ao procedimento administrativo do lançamento, sendo necessário colher as informações e declarações do contribuinte para efetuar tal mister.

Portanto, as legislações estaduais elegeram seus momentos de definiç̧ão para constituição do crédito tributário. Ocorre que em razão disso, surgiram conflitos judiciais quanto ao momento de aplicação da regra de incidência do ITCMD, em especial sobre definição de alíquotas, base de cálculo e contagem inaugural do prazo prescricional e decadencial para a exigibilidade do ITCMD.

As repostas foram expostas nas Súmulas 112, 113 e 114 do STF.

No entanto, faz-se severas críticas a edição destas súmulas, a priori, porque datam do ano de 1963 e, ademais foram editadas sob um contexto de discussões legislações já revogadas.

A Súmula 112 diz que o imposto de transmissão "causa mortis" é devido pela alíquota vigente ao tempo da abertura da sucessão. Neste caso, conclui-se que considerou-se o evento morte, para se definir a aplicação da norma. Agora, com a instituição das alíquotas progressivas, instituindo uma alíquota menor que a da data da morte. Qual a alíquota a se aplicar? 
A Súmula 113 diz que O imposto de transmissão "causa mortis" é calculado sobre o valor dos bens na data da avaliação. Neste caso, conclui-se que considerou-se a data da avaliação dos bens. Assim, já se tem um outro momento que seria a época da homologação do cálculo, que em tese fica a critério do contribuinte, visto tratar-se de um lançamento por declaração. Imagine os acréscimos patrimoniais não decorrentes da transmissão no evento morte. Em tese, o fisco aplicaria a alíquota da legislação à época do evento morte e a base cálculo aplicaria a legislação do momento da homologação do cálculo. Parece ser uma solução complexa.

A Súmula 114 diz que O imposto de transmissão "causa mortis" não é exigível antes da homologação do cálculo. Também neste caso, parece que a súmula torna impossível o instituto da decadência em matéria de ITCMD, ademais mais uma vez fica a critério do contribuinte declarar ou não, ou seja, prorrogar por qualquer prazo o lançamento do imposto. Isto também não parece razoável. Ademais, no contexto atual, inexiste a figura atual de homologação de cálculos, em processo de inventário.

Vale destacar, que atualmente, as administrações tributárias estaduais dispõem de estruturas tecnológicas que permitem trocas de informações com diversas entidades públicas e privadas, velocidade nos processamentos de dados e modernos mecanismos de controle. Isto permite, perfeitamente, alterar e ajustar suas legislações, podendo controlar eletronicamente, o número e registro de óbitos, criar obrigações acessórias e aí sim levar efetivamente todos os aspectos do momento de ocorrência do fato gerador do ITCMD para o evento morte.

Desta forma, os físcos estaduais não ficariam adstritos ao comportamento do contribuinte, já efetivamente exerceriam suas ações fiscais e minimizariam as discussões jurídicas as respeito do tema.

Assim, o momento de ocorrência do fato gerador do ITCMD é o evento morte, e todos os aspectos da definição do lançamento deste imposto reportar-se-ia a esta data, inclusive para fins de contagem de prescrição e decadência. 


\section{REFERÊNCIAS}

BRASIL. Código Tributário Nacional. Disponível em: http://www.planalto.gov.br/ccivil_03/leis/L5172.htm> Acessado em 20-03-2016.

BRASIL. Constituição da República Federativa do Brasil de 05 de outubro de 1988. Disponível em: http://www.planalto.gov.br/ccivil_03/Constituicao/Constituicao.htm $>$. Acessado em: 20-03-2016.

BRASIL. Supremo Tribunal Federal. Súmulas. Versão Resumida. Disponível em: http://www.stf.jus.br/portal/cms/verTexto.asp?servico=jurisprudenciaSumula> Acessado em 20-03-2016.

BRASIL. Superior Tribunal de Justiça. Disponível em: https://ww2.stj.jus.br/processo/pesquisa/?tipoPesquisa=tipoPesquisaNumeroRegistro\&termo= 199400376189\&totalRegistrosPorPagina=40\&aplicacao=processos.ea $>$ Acessado em 20-032016

CARVALHO, Paulo de Barros. Direito Tributário, Linguagem e Método. São Paulo: Noeses, 2008.

CARVALHO, Paulo de Barros. Teoria da Norma Tributária. $4^{\mathrm{a}}$ ed., ed. Max Limonad, São Paulo, 2002.

CASSONE, Vittorio. Direito tributário: fundamentos constitucionais da tributação, definição de tributos e suas espécies, conceito e classificação dos impostos, doutrina, prática e jurisprudência. 25 ed. São Paulo: Atlas, 2015.

COELHO, Sacha Calmon Navarro. Curso de direito tributário brasileiro. $14^{\mathrm{a}} \mathrm{ed}$. rev. e atual. Rio de Janeiro: Forense, 2015.

COSTA, Regina Helena. Curso de direito tributário: Constituição e Código Tributário Nacional. 3. Ed. São Paulo. Saraiva, 2013.

DINIZ, Maria Helena. Código Civil Anotado. 13 ed. São Paulo, Saraiva: 2008.

FERNANDES, Regina Celi Pedroti Vespero. Imposto sobre transmissão causa mortis e doação - ITCMD. $3^{\text {a }}$ ed. ver. e atual. São Paulo: Editora Revista dos Tribunais, 2013.

MACHADO, Hugo de Brito. Curso de direito tributário. São Paulo: Malheiros, 2010.

PIKETTY, Thomas. O Capital no século XXI; tradução Monica Baumgarten de Bolle, $1^{\mathrm{a}}$ ed. Rio de Janeiro: Intrínseca, 2014.

PRADO, Clayton Eduardo. Imposto sobre Herança. $1^{\mathrm{a}}$ ed. São Paulo: Editora Verbatim, 2009. 
SCHOUERI, Luís Eduardo. Direito Tributário. 5. ed. São Paulo: Saraiva, 2015.

TORRES, Ricardo Lobo. Curso de direito financeiro e tributário. 16. ed. Rio de Janeiro: Renovar, 2009. 